\title{
Teacher's Professional Development from Vygotskian Optique
}

\author{
Karim Shabani \\ (Allameh Mohaddes Nouri University, Iran) \\ doi:10.7575/aiac.alls.v.3n.2p.101
}

\begin{abstract}
Vygotsky's concept of ZPD (Zone of Proximal Development) has been recently applied to the context of language teacher education by a number of researchers (e.g. Ohta, 2005; Singh \& Richards, 2006; Nassaji \& Cumming, 2000). Besides Vygotsky's notion of ZPD, this paper relies on two associated theories from outside the TESOL discipline namely; Valsiner's (1997) Zone Theory and Blanton, Westbrook and Carter's (2005) Illusionary Zone (IZ) to provide a broad picture of the most influential variables facilitating or constraining teacher's professional development or, as specifically defined here, his ZPD progression. Several excerpts in the form of teacher comments taken from different qualitative studies in the related literature are given to lay evidence for the effect, if any, of the raised variables. Finally, the paper concludes with some practical tips for the pre/in-service language teachers as to how to keep their evolving ZPD dynamic in their long-life language teaching profession.
\end{abstract}

\section{Introduction}

As its point of departure, this paper assumes the concept of professional development in language teachers to be a function of progression in their ZPD (zone of proximal development). We examine how Vygotsky's (1978) seminal notion of Zone of proximal Development, originally developed to account for the learning potential of the child, Valsiner's (1997) Zone theory and Blanton et al's (2005) Illusionary Zone theory as pioneers of a neo-Vygotskyan approach can be applied to the concept of teacher professional development. We also make a specific attempt to see how a number of assets at the teacher's disposal namely diary writing, peer and mentor collaboration, action research, practicum and TESOL discourse can serve as scaffolders to affect the progression of ZPD in language teachers. To date, except for a few studies that were outside the ELT domain the aforesaid theories have never been collectively employed to explain the process of language teacher professional development. Hence, an exigent need to undertake the present study. To set the 
ground for our main discussion, a brief sketch of the existing theories to describe teacher's professional development or expertise is presented.

\section{Influential theories to describe professional development or expertise}

The concept of expertise has always been a thorny issue to explain for decades. The following are the most dominant approaches to expound on the nature of expertise.

\section{Information processing model}

In this view, expertise is conceived as learning some psychomotor skills which are fraught with errors at the novice stage and become subconscious, automatic, fluent, and effortless when the person gets to the advanced stage as a result of practice. Within this framework, learning is seen as the movement from controlled to automatic processing via practice. This continuing movement from controlled to automatic processing results in a constant restructuring (McLaughlin, 1987). This model of expertise appears simplistic since it can only explain the psychomotor skills and stops short of accounting for the quality of more demanding cognitive skills (Berliner, 2004; Tsui, 2003).

\section{Heuristic model}

The pioneering work to introduce the heuristic model is presented by Dreyfus and Dreyfus (1986) who have developed a five-stage model of teacher development from novice to expert. Dreyfus and Dreyfus (1986) propose that intuition, tacit knowledge and 'knowing how' lie at the heart of human expertise and argued against conscious operation or 'knowing that' in performing expert activities. This tacit knowledge is based on personal hunches and intuitions rather than a set of rules about how to operate new activities. Their proposed theory consists of five stages from novice to expert to explain the skills of acquisition, which is briefly summarized below:

Stage 1: Novice

The novice's actions are guided by rules and a set of objective facts and features related to the skills. There is little consideration for the context of the actions.

Stage 2: Advanced Beginner

After getting some experiences in applying the rules in real situations, they begin to recognize situational elements that they need to consider from their actions.

Stage 3: Competent

Competent performers are able to cope with an overwhelming amount of information and assess the situations and distinguish important from unimportant information. They are also emotionally involved with the outcome which can rarely been observed in novices and advanced beginners. 
Stage 4: Proficient

This stage is marked by the emergence of intuitions or know-how (procedural knowledge). Proficient performers are able to act without conscious deliberation since they can recall similar situations in the past and the course of actions taken that were proved effective.

Stage 5: Expert

Expert's performance is marked by effortlessness and fluidity guided by intuition. Skills become part of experts. There is no need for conscious decision making or problem solving unless a novel situation is encountered.

(Adapted from Tsui, 2003, pp. 10-11)

From this perspective, the novice teacher will turn into an expert practitioner when his 'knowing that' about language teaching develops into a 'knowing how'. His declarative knowledge acts as a springboard to acquire the procedural knowledge which is characterized by an effortless and automatic operation (Tsui, 2003).

\section{A model of cognitive psychology}

Glaser (1996) has developed a modern three-stage cognitive theory that sketches an 'abstract' conception of expertise. Inspired by Vygotskyan thinking, Glaser gives prominence to the importance of social learning, communities of practice and critical role of more significant others in shaping expertise (Berliner, 2002). Glaser (1996) sees the emergence of expertise as 'a change in agency over time'. The three phases of development by Glaser are as follows:

a. Externally supported phase: involves environmental structuring for initial acquisition of the skills needed by the novice teacher, musician or athlete. The young performer is influenced by the dedication, interest and the support of coaches, parents, practitioners in the field and others who are significant in their lives.

b. Transitional phase: is characterized by a decrease in the scaffolding used for and by the novice performer, accompanied by a concomitant increase in apprenticeship Self-regulation techniques are learned and high standards for performance begin to be set.

c. Self-regulatory phase: in this phase a developing expert controls much more of their own learning environment. The emerging expert receives the feedback they need and also chooses the level of challenge for their own development.

(Berliner, 2004, p. 478)

Expertise in this model is construed as a long-life progression. This idea had been previously developed by Bereiter and Scardamalia (1993) who defined the notion of expertise as an investment, progressive problem solving and willingness to tackle challenging problems that increase expertise. Beriter and Scardamalia (1993) argue that true expertise is not a static feature, to be achieved once and then abandoned, but a continual process over time. For expertise to get developed, routine teaching practices are not enough and teachers must continually reinvest time and energy, meet new challenges and shift their focus to new aspects of environment like the content, delivery of the content and the social and personal aspects of their students sequentially as they develop. Only in this way can novice teachers 
turn into expert teachers. Otherwise, they would remain as experienced non-experts despite benefiting from many years of practical experience. Beriter and Scardamalia (1993) go as far as to claim that the critical difference does not lie in the efficiency in problem solving, but rather, in the kinds of problems the experts and non-experts solve. They contend that experts tackle problems that 'enhance' their expertise by working 'at the edge of their competence', whereas non-experts tend to engage in problems for which they don't have to extend themselves. The experienced non-experts try to base their approach to the new task or problem on a narrow vision and constantly try to minimize rather than maximize their opportunities for growth. Non-experts tend to reduce their activities to some routine practices but the experts always 'problematize' their routine behaviors (Beriter \& Scardamalia, ibid).

This model is against Dreyfus and Dreyfus's (1986) model since it treats expertise as a 'process' rather than a state. Dreyfus and Dreyfus's model, according to this model, doesn't elaborate on how the novice actually acquires the expertise, nor can it distinguish between experts and experienced non-experts. Beriter and Scardamalia give examples of drivers who are not judged as good drivers despite having many years of driving experience and fluent writers who are still bad writers despite going through all the five stages of skill development from conscious rule learning to automatic operation. Drawing on Ericsson and Smith (1991), one's number of years of experience can not be taken as an accurate measure of one's level of expertise. It is this line of presenting the concept of learning that the present paper intends to follow in order to examine how the teacher's ZPD is triggered and kept dynamic such that it will finally change the novice teacher into an expert practitioner. Or, as in Rogers' words, "The only man who is educated is the man who has learned how to adapt and change; the man who has realized that no knowledge is secure; that only the process of seeking knowledge gives a basis for security" (Rogers, 1969, p.104).

In order to paint a clear picture of ZPD progression, clarification of some basic assumptions underlying the concept is quite necessary. First, a brief review of Vygotsky's ZPD along with the associated theories is presented. Then, an attempt is made to see how these theories can explain the process of teacher development. 


\section{Vygotsky's Zone of Proximal Development}

As one of the most influential concepts ever coded to account for the quality of first as well as second language development, ZPD originally developed by Vygotsky has gained footing in L1 and L2 researches (Ohta, 2005; Goos, 2005a). Vygotsky defined the ZPD as

\footnotetext{
The distance between the actual developmental level as determined by independent problem solving and the level of potential development as determined through problem solving under adult guidance or in collaboration with more capable others. (Vygotsky, 1978, p.85)
}

ZPD is conceived as a multistage progression and continuum rather than a single point in time. It is realized through a collaborative, intersubjective, and asymmetric interaction between the child (a novice) and a more significant or knowledgeable other that can be a parent, a teacher or peer (Vygotsky, 1978).This progression occurs between two points, namely the child's current developmental level as the starting point and its next level of development as the endpoint. This movement from an ability to accomplish a task with the help of an interactive collaborator to a higher ability or state to accomplish the same task independently is called 'learning' in Vygotskyan terms (Vygotsky, 1934). Others have referred to these two points as 'independent performance' and 'assisted performance' respectively (Goos, 2005b). The following figure depicts these two points clearly:

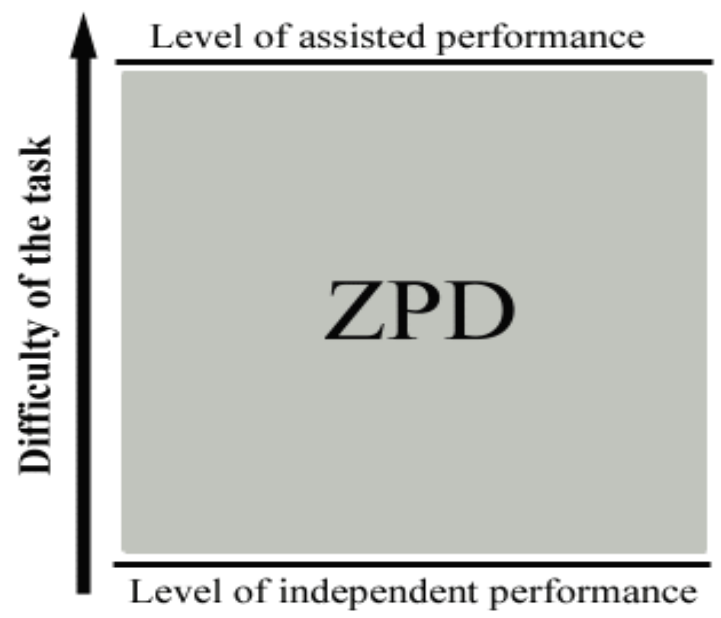

Figure 1: ZPD representing a continuum (Bodrova \& Leong, 1995)

The bottom line here is that "what the child is able to do with some collaboration or assistance today he will be able to do independently tomorrow" (Vygotsky, 1934, p. 211). This shift from an interpsychological, other-regulated acting to an intrapsychological selfregulated state in an interactive and supportive microgenesis occurs spirally (Hickman, 1986). After moving from his present ability to his next (potential) ability with some 
assistance, the child will define a new potential ability by drawing on his genetic capacity and changes his previous potential ability as the springboard to reach a new potential ability. This cycle is repeated over and over again when the child learns different kinds of tasks, skills and behavior. Thus, child's ability to perform more difficult tasks is gained as a result of several 'internalization' processes (Vygotsky, 1934) at different times progressively as is shown in figure 2 overleaf:

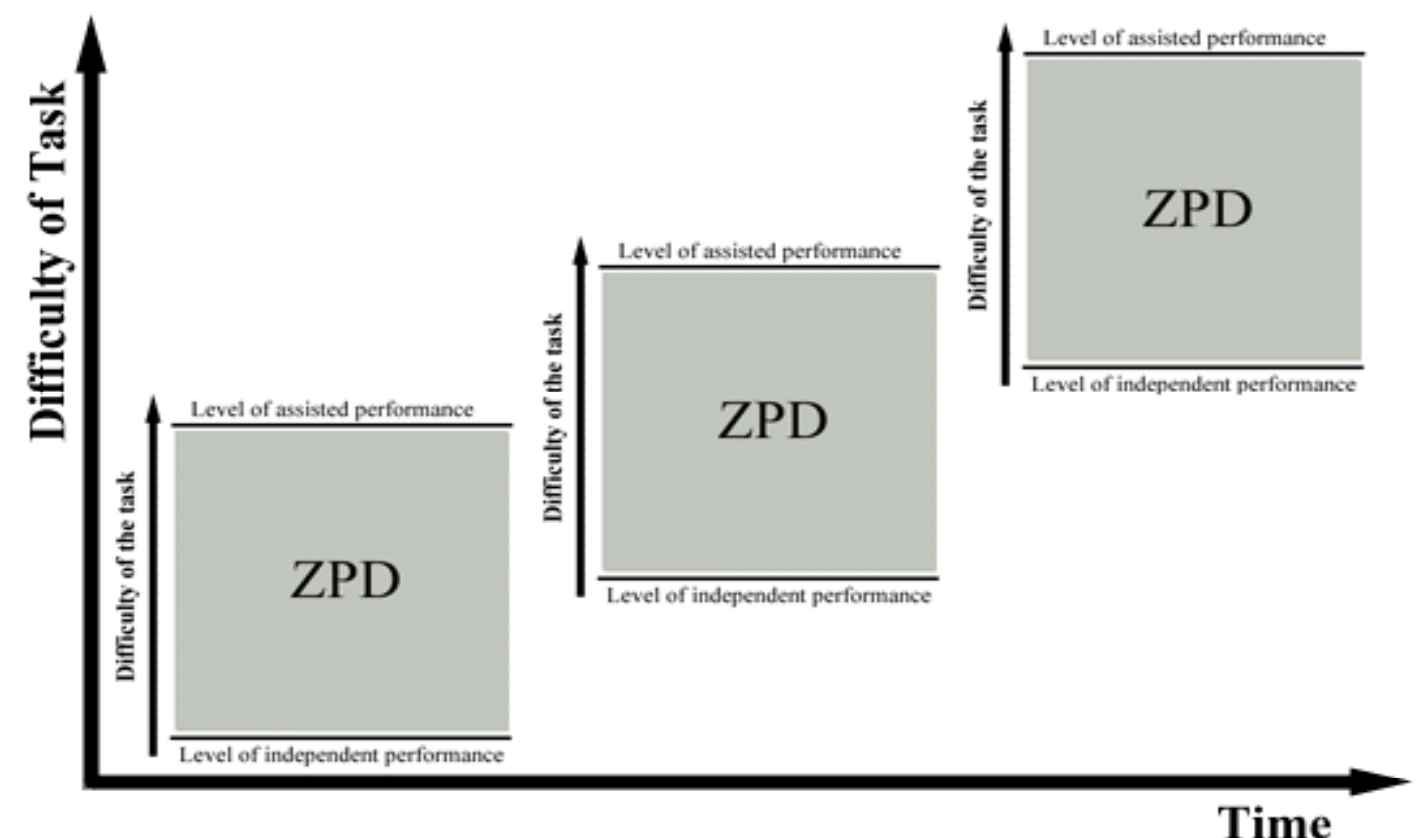

Figure 2: ZPD in progress (Bodrova \& Leong, ibid)

The application of ZPD to SL learning assumes that new language knowledge is jointly constructed though collaborative activity between the supportive teacher and the learner who acts as an active agent to construct his own knowledge of language when appropriate assistance consistent with his current ZPD is given.

ZPD progression is triggered by 'scaffolding' which is defined as any kind of teaching and instructional mediation that proves conducive to learning. Scaffolding takes such different forms as cuing, feedback and encouragement that can help learners develop cognitively. Scaffolding can be offered cognitively, emotionally (affectively) (Rosenshine \& Meister, 1922) and even 'technologically' (Yelland \& Master, 2005). The latter is provided through computer and related software as mediators for learning since they can provide the appropriate context for successful learning (Yelland \& Master, ibid). Lantolf (2004) contends 
that scaffolding can 'open the learner's zone of proximal development' through self, peer, social and artifact mediation.

In his theory, Vygotsky has repeatedly mentioned that any kind of help presented to the learner must be consistent with his current level of development, otherwise learning would not occur. However, the gap between the learner's present and potential ability or ZPD, is not the only factor influencing future development. Other factors like contextual constraints may also play a part to influence the learning process. To crystallize this issue, the model developed by Valsiner (1997) seems more illustrative.

\section{Valsiner's Zone Theory}

Having been preoccupied with developmental psychology, Valsiner (1997) extended Vygotsky's concept of ZPD and added two other zones which he called the Zone of Free Movement (ZFM) and the Zone of Promoted Action (ZPA). ZFM is the kind of action set by the adult that the child/learner is allowed to undertake and the level of cognitive thinking he is exposed to (Valsiner, 1997). Goos (2005a) defines ZFM as a zone structuring:

- an individual's access to different areas of the environment;

- the availability of the different objects within an accessible area; and

- the ways the individual is permitted or enabled to act within accessible areas.

ZPA is a set of actions the teacher promotes in the student as a result of his scaffolding (Warren, Cooper \& Lamb, 2006). Goos (2005a) defines ZPA as a zone reflecting the person's promotions made in a related environment influenced by the activities, objects or areas in the milieu. The critical point here is that due to the constraints available and some unpredictable problems arising during the implementation phase of the learning tasks, the teacher's or even the student's intended and ideal level of learning will never be attained. This is what Blanton et al. (2005) have called Illusionary Zone (IZ). The IZ of promoted action is not allowed to be actualized due to the restraining factors existing in the ZFM. The interrelationship between ZPD, ZFM, ZPA and IZ is shown in figure 3 below. 


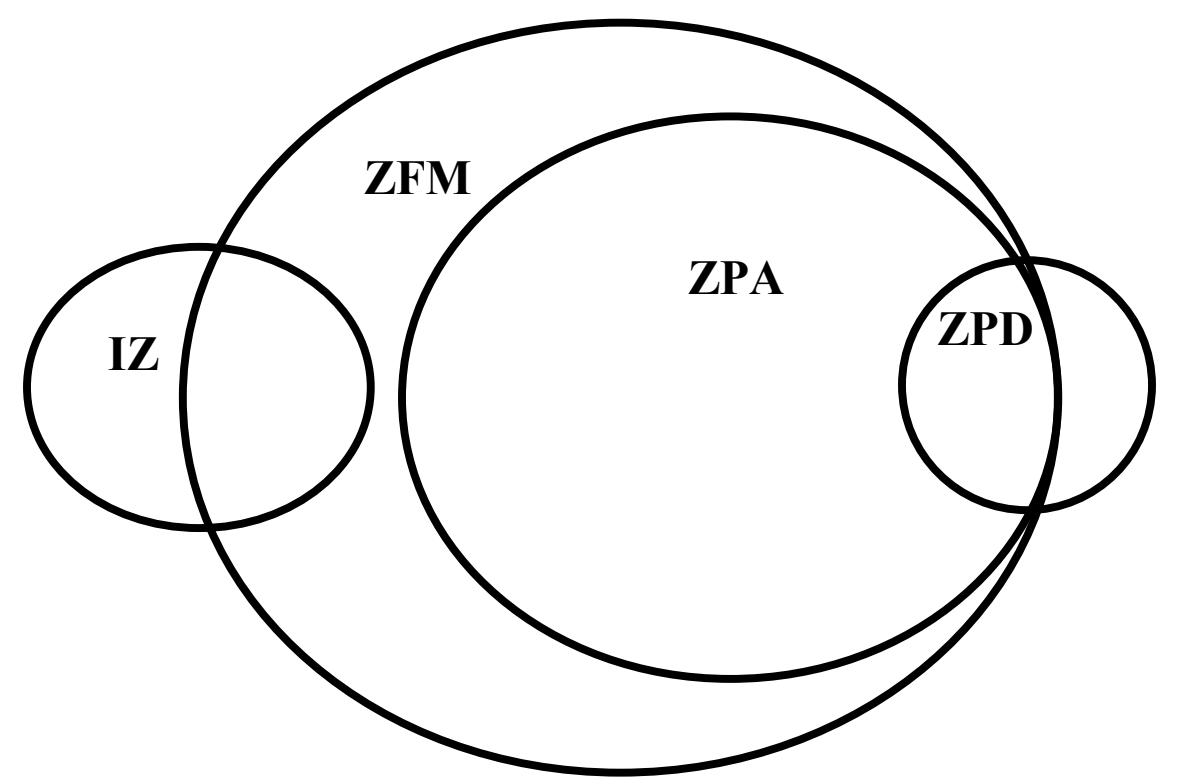

Figure 3: Overlapping of ZPD, ZPA, ZFM and IZ (Blanton et al., 2005)

The aforesaid discussion inspires us to see how Vygotsky's ZPD, Valsiner's Zone Theory and Blanton et al's Illusionary Zone can be applied to the context of teacher professional development.

\section{ZPD in language teachers}

The teacher's zone of proximal development is thought as a learning space between his present level of teaching knowledge consisting of content (theoretical) and pedagogical knowledge and skills and his next (potential) level of knowledge to be attained with the support of others (Blanton et al., 2005). This definition provides us with the possibility not to restrict ourselves to regard teacher educator as the only source of scaffolding and think of some other sources like the teacher's colleagues, researchers in the field (TESOL community), student achievement data, narratives, observation, action research, pre-service and in-service LTE course-room, etc. as other possible sources of scaffolding that can change the teacher's ZPD.

\section{ZPA in language teachers}

The teacher's ZPA is the actual set of promotions made in the practicing teacher in the form of a received teaching strategy or technique, a well-informed teaching approach, or any practical tip to cope with the on-the-spot language teaching or classroom management problems (Goos, 2005a). The pre-service teacher educator, professional development (in- 
service) activities and colleagues in the school and university setting can help build ZPA for language teachers (Goos, 2005).

\section{ZFM in language teachers}

The wide range of contextual or environmental constraints that impose restrictions on the teacher's freedom of action and decision making builds his ZFM that includes the students' behavior, motivation, perceived abilities, curriculum and assessment requirements, syllabus standards, availability of teaching resources and technology and a host of other factors affecting the teaching and learning process in a specific context (Goos, 2005). The ethical and academic standards governing the classroom behavior set by the local institution or even the country's ministry of education can shape a certain ZFM for the teacher. The ZFM determines which teaching actions are possible (Goos, 2005, p.4). The rules imposed on a teacher's ZFM limit his rights and freedom to select one or the other teaching method/strategy which may or may not even sound ethical (Pennycook, 1997). The ZFM includes such elements as:

1. The students, whose abilities and behavior may constrain teaching actions;

2. The curriculum embodied in the school work program and supported by prescribed textbooks, which influences choice of topics and teaching methods;

3. Resources, in the form of audiovisual aids, materials for practical classes, reference books, or specially equipped classrooms, whose availability has a bearing on teachers' planning decisions;

4. Time constraints, in particular, the need to cover a specified amount of "content" within a limited time period (whether this be the lesson or the school year); and

5. The relationship between student teacher and supervising teacher, and the extent to which their beliefs about teaching and learning coincide.

(Goos, 2005: my italics)

\section{IZ in language teachers}

The final zone that merits attention is the Illusionary Zone which is defined as

a zone of permissibility that the teacher appears to establish through behaviors and routines used in instruction but in reality does not allow... IZ [is] that which appears to be promoted but in fact was not allowed. (Blanton et al., 2005 quoted in Warren et al., 2006)

One main instigator to trigger IZ is the mismatch between the teacher's ideal goals and the goals imposed on him by the local institution (Warren, et al., 2006). In order for professional development to get actualized, the assisted performance or promotion (ZPA) must be rendered within the scope and framework of the existing norms of the context and the teacher's ZFM. In other words, to gain an ideal level of learning, the ZPA offered by the 
colleagues, researchers and in-service teacher educators must be within the teacher's ZFM and also in line with his ZPD. As long as the required promoted actions (ZPA) do exceed the existing (ZFM), the IZ continues to appear as the optimal and intact distance to tap.

The starting point for teacher learning is the teacher's willingness and motivation to keep his ZPD in motion so as to move from the current ZPD to a more advanced ZPD in his teaching profession. If the prospective novice teacher is determined to improve his act of teaching, he must engage in that shifting process and continuously define new ZPDs. Otherwise, he would remain as an experienced non-expert teacher with a stagnant ZPD (Beriter \& Scardamalia, 1993).

\section{Presumed factors affecting teachers' ZPD}

To enhance ZPD progression, teachers need to continually define new goals or IZs throughout their teaching life. Their prior experienced passive learning and blind dependence on other teachers usually hinder the teachers from theorizing their 'own' pedagogical knowledge and from moving up through their ZPD. To do so and avoid a dormant teaching life, teachers need to make a change in their career and go through 'professionalism', and determine their own tasks in the classroom and the ways to develop, negotiate, use and control one's knowledge (Helsby \& McCulloch, 1996). Drawing on Nielsen et al. (2007), the influential factors contributing to the professional change come from two main sources either from 'within' such as a teacher's knowledge, belief, and self-efficiency, or from 'outside' the teacher such as the school, community, etc. The following is a set of influential factors both internal and external, that are presumed to have direct effect on the teachers' zone of proximal development and professionalism:

a. Collaborative peers and mentors

b. Contextual constraints

c. LTE Course room and TESOL discourse

d. Mediatory artifacts and technology

e. Action research and student achievement data

f. Diary writing

a. Collaborative peers and mentors: The idea that teachers do benefit from the encouragement and support of their collaborative colleagues and coaches is widely accepted. As Tschannen-Moran, Woolfolk-Hoy and Hoy (1998) hold, the increased collaboration with either supportive colleagues or literacy coaches can support teachers when they seem to lose 
their self-confidence due to a lack of experience and self-efficacy. Nielsen et al. (in press) suggest that one way to bring about professional growth is to attend the classes conducted by 'exemplary teachers' and 'coaches' and observe their teaching methods, strategies and techniques. The following comment written by one of the teacher learners in Nielsen et al's qualitative study illustrates the importance of instructional role models since they can provide opportunities for the novice teachers to study different instructional methods in multiple contexts:

Seeing somebody else put it together and put it in action was...I mean I learned so much that week from the other teachers. Even though we're all doing... across the board, in kindergarten the way that they used it was different, so I could pick up pieces of that to incorporate into my classroom. (Nielsen et al., in press, p. 5)

As this excerpt displays, observing an exemplary teacher's models of teaching can be enlightening. Other studies indicate that this way of teacher learning i.e. observation will be more fruitful when the exemplary teachers and coaches teach in the teacher's own classes so that $\mathrm{s} /$ he can observe how the model teachers can cope with their 'context-dependent' teaching problems (Nielsen et al., ibid). The collaborative guidance provided by the peers or mentors for the teachers could also be provided on-line via internet. Teachers could engage in journal writing to share their practical problems with more experienced teachers on line at any time and get immediate feedback.

b. Contextual constraints: Teacher's freedom of action and decision making are always constrained by contextual factors. Some of the decisions made in the class by the teacher are affected by the outside forces which originate in social, economic, political or educational policies. In other words, the microcontext of the classroom is, to some extent, shaped by the larger sociopolitical macrocontext (Singh \& Richards, 2006). One factor to narrow teachers' IZ and restrict his personal choices, goal setting and activities is compliance with the norms prescribed and imposed by the local school or institution the teachers work in. This can be understood from the words of a teacher in Neilsen et al's study claiming

It was almost negative. We were told at our first meeting, You will be doing Writer's Workshop this year. It was just like orders from the high holies or something like that. (Nielsen et al., in press, p. 10)

The local school may, sometimes, exert its pressure on the teacher's freedom to select his method of evaluation. Brouwer and Korthagen (2005) give the example of a context in 
which the teachers have to provide quantitative outcome measures for their students' learning in order to meet parents' as well as institute's expectations. The following comments by two teachers in their study prove good evidence

This school is crazy with grades. This system of 'progress cards' is meant to prevent parents from complaining about grades when it's too late. The school obliges me to produce grades for selection purposes. I do so, but not wholeheartedly, because I think dropouts aren't stupid. They just get too little attention in school. (Brouwer \& Korthagen, 2005, p. 209)

c. LTE course room and TESOL discourse: The current ideas as to the value of course room during practica and internships do not advocate the traditional notion of teacher training based on 'transmissional' ideology because it is believed that teaching is not a blend of discrete behaviors that can be distanced from the contexts in which they occur and a readymade package or raw material to be transferred to the novice teachers (Singh \&Richards, 2006). Rather, the teachers' content and pedagogical knowledge, his own previous experiences of language learning, cognitive and thinking skills and beliefs are taken as reliable resources to draw on for constructing personal theories of language teaching (Freeman, 2001). Teacher's professional knowledge is not static, but continually reshaped by the contextual conditions of the classrooms and schools in which the teachers are working (Freeman, 2001).Singh and Richards (2006) adopt a critical sociocultural perspective to look at the nature of teacher learning in the LTE (language teacher education) course-room. They believe that learning is shaped within institutional, historical and cultural contexts and the course room is conceived as a 'community of practice' for the teacher learners who must feel accountable for constructing their own theory of pedagogy. In the course room, teachers are encouraged to engage in 'personal theorizing' based on their own experiences, beliefs and understanding of the language. The course room is looked at as a site for developing 'professional', 'transformative' teachers who will turn into critical reflective practitioners and autonomous agents (Singh \& Richards, 2006). Transformative teachers move from the role of being consumers of outside expert knowledge towards taking an active role as curriculum developers and researchers of their work (Singh \& Richards, ibid).

As a valuable site for 'collaborative learning', the course room can provide the chance for the apprentices (teacher learners) and teacher educators to engage in collaborative dialogue to solve practical teaching problems so as to come up with new forms of knowledge. As an example, the teacher educator can bring a videoed lesson to the class and ask the student 
teachers to think of the ways to teach a tricky language point or grammatical structure in the class. They raise their own underlying ideas and understanding of the raised problem and finally agree upon a reliable pedagogical principle that sounds most effective (Singh \& Richards, 2006). An associated advantage of the course room is to get teachers more acquainted with the dominant TESOL discourse. Singh and Richards expound on the benefits of LTE course room in which the teacher learner can acquire a special 'discourse' that consists of

- The dominant discourse of TESOL (e.g. learner-centeredness, learner autonomy, authenticity, genuine language, accountable learning, and some version of communicative methodology and the four skills;

- Ways of acting and interacting (e.g. how to be a teacher learner on an MA course in the US, UK, Australia or elsewhere);

- Acquiring the appropriate cultural practices in the course room (e.g. how to write a term paper in the appropriate style, how to pose questions and respect different points of view) and

- Enacting the identity of a teacher learner

(Singh \& Richards 2006, p.156)

d. Mediatory artifacts and technology: The next triggering factor to influence teacher learning is the 'mediatory artifacts' which include technology, handouts, worksheets, video, physical classroom layout, etc. (Singh \& Richards, 2006). Technology has proved to serve as a reliable source of electronic scaffolding and, thus, a positive change in teacher's professional development. Internet, computer and associated software known as technological artifacts can mediate teacher's learning (Lantolf, 2004). CMC (computer mediated communication) as a source of mediation for learning is based on the idea of 'tool mediation' that stems from Vygotsky's work, embracing both 'symbolic' and 'physical' mediation (Lantolf, ibid). The hardware aspect of CMC including chat rooms, computers, websites, blogs, vlogs, etc. can help establish an indirect or mediated relationship between the teachers and the world (Yelland \& Master, 2005).

As for teacher learning and development, the internet and services offered can create a space for the teachers to share their teaching methods, techniques, instructional experiences and strategies with other colleagues and mentors on line and receive beneficial feedback on the quality of their evolving personal beliefs, assumptions, and knowledge about their learning and teaching at different phases of their teaching practice, that is, at the beginning, during and at the end of their instructional courses (Kumaravadivelu, 2001). Similarly, Web can offer a 
vast and continually growing library to the teacher in order to keep abreast of the recent know-how in TESOL (Nielsen et al., in press).

Angeli and Valanides (2004) tested the effect of providing electronic scaffolding in the form of Filamentality i.e. "a fill-in-the-blank interactive Web site that assists [teacher] learners in defining a topic, and guides them through searching the Web and collecting appropriate Web sites" (2004, p.32) on teachers' PTE (Perceived Task Effort) when they manage to create instructional activities for their classes. They found that knowing how to surf the Web in order to find useful sites for a typical topic for the class would lower the teacher's cognitive load and increase his level of confidence. However, the lack or paucity of technology may impede a successful teaching and this would result in a poor learning on the part of students. Teacher's smooth activities in the class depends on the degree to which the technological logistics like internet, laboratory, video, video projector, computer, CDs, etc. are available.

e. Action research and student achievement data: To keep abreast of state-of-the-art teaching, action research can provide the ground for the teacher learner to test different teaching methods and activities in the class and get feedback from the students so as to revise and develop his underlying understanding of language teaching and learning processes. As an exercise of reflective teaching and a point of departure from acting as a consumer of an outside expert, action research provides an inside-out approach to professional development placing the teacher at the heart of teaching inquiry (Nunan, 2001). Oxford (2001) considers action research as a tool to elicit information about the students' language and cultural background, motivation, gender, age, preferences, learning strategies and styles so that teachers can provide strategy instruction that the concerned students need. Through action research, the teacher can test different theories of language teaching in his class to see if they work and finally get feedbacks from the students. Action research can provide a tool for the teacher to make a link between his theoretical and practical knowledge advocating a more active role for the teacher and, hence, a step towards teacher autonomy (Kumaravadivelu, 2001). Kumaravadivelu (2001) regards 'action research' as an effective way to develop teacher's professionalism and as a site for self-exploration and self-improvement. He presents the following suggested ways to embark on action research:

- using questionnaire, surveys and interviews to collect data about learning strategies, styles, attitudes, etc. 
- identifying research questions

- exploring the learners' sociocultural and linguistic knowledge to exploit for learning

- engaging in self-evaluating

As a reliable method to receive feedback from the students, questionnaire can provide the teacher with immediate, first-hand information about the quality of his teaching and the need to change or improve his teaching style and behavior. The following excerpt from Brouwer and Korthagen (2005) is quite revealing:

What I am consistent about, though, is having pupils fill in a questionnaire once a year, where they can indicate how they feel about my lessons. From these questionnaires, I try to draw my conclusions... They like filling out such a questionnaire and they're serious about it. Of course, I learn about the conclusions and I try to use them to improve my teaching. (Brouwer \& Korthagen, 2005, p. 209)

f. Diary writing: Diary as a tool at the teacher's disposal is the "first person account of one's own language learning or teaching experience writing candid entries in a personal journal for later review and analysis" (Bailey, 1990, p.215). In diary writing, the teacher provides a genuine picture of his teaching practice either during or after the teaching session. To learn from diaries, teachers must feel free to reflect, experiment, criticize, doubt, express frustration, and raise questions in the journal (Bailey, ibid). Then, he should embark on postactivity reflection and ask the following questions to analyze his diaries:

1. What did I intend?

2. How did I come to be this way?

3. How might I teach differently?

4. What and how shall I now teach?

(Bartlett, 1990)

It is also recommended that the practicing teacher read other teachers' diaries and, then, compare his own teaching experiences and instructional models with those of other teachers (Nielsen et al., in press). A crucial benefit of diary writing is to raise teacher's awareness about the quality and validity of his teaching practice. The following comment by a teacher in Telatnik's research corroborates this hypothesis:

After having analyzed myself daily I tended to see other people's analysis of my teaching more objectively. Having learned to be honest and objective in my own recording, I found is easier to be more honest and objective about others' comments... With Observer X, who criticized my authorization, teacher-dominated approach, I began to become less defensive. My resentment passed when I accepted the fact that I did run a teacher-dominated classroom and that was exactly what I wanted. I no longer secretly raged through our discussions. I even managed to 
glean from our sessions a few techniques on encouraging student participation. (Telatnik, 1978, pp7-8)

In sum, the real expert teacher is the one who reflects on his teaching. This idea echoes Berliner's stance towards the concept of expertise claiming that experience will only contribute to expertise if practitioners are capable of learning from it and to learn from experience requires that practitioners constantly reflect on their practices (Berliner, 2004).

\section{Discussion and conclusion}

Throughout the article, an attempt was made to provide some insights into the concept of professional development. A sociocultural view of learning was taken as the ideal approach to account for the teacher's professional development. A brief sketch of three models namely Vygotsky's zone of proximal development, Valsiner's Zone Theory and Blanton et al's IZ were provided to shed some light on the most significant variables in terms of affordances or constraints affecting the teacher's professional change. These variables were discussed as the main determinants of professionalism. As outlined in this article, teacher's professional development or ZPD progression gets actualized as a result of multiple interactions among several factors. The point of departure for the teacher to engage in learning and professional change is his willingness and strong desire to get away from his current ZAD and to head towards ZPD. The retrogressive teachers are usually satisfied with their routine skills and teaching abilities and never risk improving their potentialities. For them, the ZPD is static and never changes from time to time. Such teachers are the ones who will turn into experienced non-expert teachers after having some years of teaching experience. They will condescend to getting used to the same routine practices. Quite contrarily, the progressive teachers benefit from a volatile and dynamic ZPD. They are always engaged in defining new ZPDs and are strongly motivated to bring about changes in their teaching practices. When teachers move from their ZAD to their ZPD, they go through a cognitive change, experience internalization and develop mentally. A number of influential factors have been taken on board in this article as the main motivators of ZPD progression.

The scaffolding offered by the supportive and collaborative colleagues in terms of instructional models, teaching tips and affective support acts as a strong motivator for teacher's ZPD progression. However, the assistance provided should fall within the teacher's ZPD and ZFM, that is, the teacher learner must be cognitively mature to grasp and, then, implement the suggested teaching strategy. Moreover, the conditions available such as the 
students' willingness to embrace the new teaching strategy, the degree of freedom allowed by the institution to welcome innovative strategies and the required textbook or materials (ZFM) must be compatible with the teacher's ZPD and ZPA if ideal progression is supposed to occur. The significance of scaffolding as a direct source of ZPD growth is quite apparent in the LTE course room and peer collaboration but its emotional aspect and the way it is offered needs further investigation.

One central issue brought to light in this study concerns the role of social interaction as a basis to foster the development of ZPD. Only when the 'social' aspects of teacher learning are taken on board to account for professional development can one claim about the applicability of Vygotsky's sociocultural theory to teacher development. To accredit this claim, this paper offered some socially-inspired factors that lead to teacher's interpsychological development, which include the LTE course room, mediatory artifacts, on-line journal writing, and collaboration peers or mentors, all of which resting on the concept of inter-psychological mediation. From among the main factors discussed in this study as the main determinants of teacher's professional development, the 'contextual constraints' are the only one that would inhibit teacher's progress to reach the zenith of his career while the others offer the required bedrock for his professional development. The main distinguishing feature between the expert and experienced non-expert teacher springs from the fact that the former continually struggles to get rid of the surrounding contextual forces and tries to make his voice heard in his teaching context. He does not take the external pressures and constraints for granted. The expert teacher's thinking rests on the belief that professional development is never-ending and lifelong. This statement is commensurate with Roger's concept of 'experiential learning' that he defines as a continuing openness to experience and a preparedness to become involved in the process of change (Rogers, 1969).

This never-ending character of ZPD posits that teachers should never stop constructing new ZPDs. They are continually engaged in defining new ZPDs throughout their teaching life mostly in the form of new professional activities, goals and promotions. Therefore, teachers' ZPD undergoing continuous transformations will gradually move the teacher up closer to her professional ideal (Glaser, 1996). However, the progression of teacher's ZPD is contingent upon multiple factors, for example the teacher's own capability and intelligence (ZPD) to internalize the assistance (ZPA), his personal beliefs and teaching philosophy (ZPD) to match or mismatch those of the mentors (ZPA), the students 
motivation and desire to welcome new activities (ZFM), the curriculum and assessment requirements (ZFM), and the availability of logistical support or technology (ZFM) in the related teaching context.

In short, the pre/in-service teachers who aspire to experience professional development could benefit from a range of options such as diary writing, electronic dialogue journal, action research, observation, collaborative peers and mentors, LTE course room, TESOL discourse, conferences and workshops, and technological scaffolding so as to bring about a life-long professional change in their ZPD. 


\section{References}

Angeli Ch. \& Valanides N. (2004) The effect of electronic scaffolding for technology integration on perceived task effort and confidence of primary student teachers. Journal of Research on Technology in Education, 37 (1), 29-43.

Bailey K. M. (1990) The use of diary studies in teacher education programs. In J. C. Richards and D. Nunan (eds.), Second Language Teaching Education, (pp. 215-240). CUP.

Bartlett L. (1990). Teacher development through reflective teaching. In J. C. Richards and D. Nunan (eds.), Second Language Teaching Education, (pp. 202-214). CUP.

Bereiter C. \& Scardamalia M. (1993) Surpassing ourselves: An inquiry into the nature and implications of expertise. Chicago: Open Court.

Berliner D. C. (2004) Describing the behavior and documenting the accomplishments of expert teachers. Bulletin of Science, Technology and Society, 24 (3), 200-212. SAGE Publications.

Berliner D. C. (2002) Learning about and learning from expert teachers. International Journal of Educational Research, 35, 463-482.

Blanton M. L., Westbrook S. \& Carter G. (2005) Using Valsiner's zone theory to interpret teaching practices in mathematics and science classrooms. Journal of Mathematics Teacher Education, 8, 5-33.

Bodrova E. \& Leong D. J. (1995) Tools of the mind: The Vygotskyan approach to early childhood education. New York: Merill/Prentice-Hall.

Brouwer N. \& Korthagen F. (2005) Can teacher education make a difference? American Educational Research Journal, 42 (1), 153-224.

Dreyfus H. L. \& Dreyfus S. E. (1986) Mind over machine. New York: Free Press.

Ericsson K. A. \& Smith J. (1991) Prospects and limits of the empirical study of expertise: An introduction. In K. A. Ericcson and J. Smith (eds.), Towards a General Theory of Expertise: Prospects and Limits, (pp. 138). CUP.

Freeman D. (2001) Second language teacher education. In R. Carter and D. Nunan (eds.), The Cambridge Guide to Teaching English to Speakers of Other Languages, (pp. 72-79). CUP.

Glaser R. (1996) Changing the agency for learning: Acquiring expert performance. In K. A. Ericcson (ed.), The Road to Excellence: The Acquisition of Expert Performance in the Arts and Sciences, Sports and Games, (pp. 303-311). Mahwah, NJ: Lawrence Erlbaum Associates.

Goos M. (2005) Theorizing the role of experience in learning to teach secondary school mathematics. In Chick H. L. and Vincent J. L. (Eds.), Proceedings of the $29^{\text {th }}$ Conference of the International Group for the Psychology of Mathematics Education, 3, (pp. 49-56). Melbourne: PME.

Goos M. (2005a) A Sociocultural analysis of the development of pre-service and beginning teachers' pedagogical identities as users of technology. Journal of Mathematics Teacher Education, 8, 35-59.

Goos M. (2005b) A sociocultural analysis of learning to teach. In H. Chick \& J. Vincent (eds.), Proceedings of the $29^{\text {th }}$ Annual Conference of the International Group for the Psychology of Mathematics Education, 3 , (pp. 49-56).

Helsby G. \& McCulloch G. (1996) Teacher professionalism and curriculum control. In I Goodson, \& A. Hargreaves (eds.), Teachers' Professional Lives, (pp. 56-74). London: Falmer Press.

Hickman M. (1986) Psychological aspects of language acquisition. In P. Fletcher and M. Garman (eds.), Language Acquisition (pp. 9- 29). CUP.

Kumaravadivelu B. (2001) Toward a postmethod pedagogy. TESOL Quarterly, 35 (4), 537-560.

Lantolf J. P. (2004) Sociocultural theory and second language acquisition. In R. B. Kaplan (ed.), The Oxford Handbook of Applied Linguistics, (pp. 104-114). OUP.

McLaughlin B. (1987) Theories of second language learning. London: Edward Arnold.

Nassaji H. \& Cumming A. (2000) What's in a ZPD? A case study of a young ESL student and teacher interacting through dialogue journals. Language Teaching Research, 4 (2), 95-121.

Nielsen D. C., et al. (in press) Teachers' reflections of professional change during a literacy-reform initiative. Teaching and Teacher Education, doi:10.1016/j.tate.2007.01.015.

Nunan D. (2001) Action research in language education. In D. R. Hall and A. Hewings (eds.), Innovation in English Language Teaching: a Reader, (pp. 197-207). Routledge.

Ohta A. S. (2005) Interlanguage pragmatics in the Zone Proximal Development. System, 33, 503-517.

Oxford R. L. (2001) Language learning strategies. In R. Carter and D. Nunan (eds.), The Cambridge Guide to Teaching English to Speakers of Other Languages, (pp. 166-172). CUP.

Pennycook A. (1997) Critical applied linguistics and education. In R. Wodak and D. Corson (eds.), Encyclopedia of Language and Education. Vol. 1: Language Policy and Political Issues in Education, (pp. 23-31). Dordrecht, Netherlands: Kluwer Academic.

Rogers C. R. (1969) Freedom to Learn. Columbus, Ohio: Charles Merrill.

Rosenshine B. \& Meister C. (1922) The use of scaffolds for teaching higher-level cognitive strategies. Educational Leadership, 49(7), 26-33. 
Singh G. \& Richards J. C. (2006) Teaching and learning in the language teacher education course room: a critical socio-cultural perspective, 37(2), 149-175. SAGE Publications.

Telatnik M. A. (1978) The intensive journal as a self-evaluative instrument for the ESL teacher. Unpublished master's thesis, University of California, Los Angeles.

Tschannen-Moran M. A., Woolfolk-Hoy \& Hoy W. K. (1998) Teacher efficacy: Its meaning and measure. Review of Educational Research, 68(2), 202-248.

Tsui A. B. M. (2003) Understanding Expertise in Teaching. CUP.

Valsiner J. (1997) Culture and the Development of Children's Actions A Theory of Human Development $\left(2^{\text {nd }}\right.$ ed.). Chichester: John Wiley \& Sons.

Vygotsky L. S. (1934) Thinking and speech. In R. W. Rieber \& A. S. Carton (eds.), The Collected Works of L. S. Vygotsky, Vol. 1, Problems of General Psychology, (pp. 39-288). New York: Plenum Press.

Vygotsky L. S. (1978) Mind in society: The development of higher psychological processes. Cambridge, MA: Harvard University Press.

Warren E., T. Cooper \& Lamb J. (2006) Teacher professional development in patterns and algebra: Being sensitive to a teacher's Zone of Proximal Development. Retrieved from http://www.merga.net.au/ documents/RP632006.pdf).

Yelland N. \& Master J. (2005) Rethinking scaffolding in the information age. Computer and Education, 48, $362-382$. 